\title{
Mercury speciation in gypsums produced from flue gas desulfurization by temperature programmed decomposition
}

Manuela Rallo, M. Antonia Lopez-Anton*, Ron Perry and M. Mercedes Maroto-Valer

Energy and Sustainability Research Division, Faculty of Engineering, University Park, University of Nottingham, Nottingham, NG7 2RD, United Kingdom

*Corresponding author

Phone: +34 985119090

Fax: +34 985297662

e-mail: marian@incar.csic.es 


\begin{abstract}
Temperature programmed decomposition was used to identify mercury (Hg) species in gypsum samples produced from flue gas desulfurization in two Spanish power stations (A and B). As stricter emission control/reduction policies, particularly those focusing on $\mathrm{Hg}$, are being implemented, wet flue gas desulfurization (FGD) technologies used for the removal of $\mathrm{SO}_{2}$ can result in the co-removal of highly-soluble oxidized Hg. The amount of Hg retained in FGD products may increase in the future if these units are optimized for co-capture. For this reason, it is important to identify the mercury species in FGD products not only to determine the potential risk when the wastes are finally disposed of, but also to understand the behaviour of mercury during combustion and therefore to improve the technologies for mercury removal. Different mercury species were identified in the gypsum samples. In power station $\mathrm{A}, \mathrm{Hg}-\mathrm{S}$ were the most probable $\mathrm{Hg}$ species, whereas in power station B the main compound was Hg halogenated compounds.
\end{abstract}

Keywords: mercury; gypsum; coal combustion 


\section{Introduction}

Coal-fired plants have been identified as the largest anthropogenic sources of mercury emissions to the atmosphere [1-2]. The European Commission launched the EU's Mercury Strategy in 2005 [2]. It is a comprehensive plan addressed to mercury pollution which contains 20 measures to reduce mercury emissions, cut supply and demand and protect against exposure [3].

During coal combustion, $\mathrm{Hg}$ can be present in different oxidation states, mainly elemental $\operatorname{Hg}(0)$ and oxidized [4], and while $\operatorname{Hg}(0)$ is volatile, relatively inert and virtually insoluble, $\mathrm{Hg}$ (II) is water-soluble. Therefore, wet FGD technologies used for the removal of $\mathrm{SO}_{2}$ can result in the co-removal of highly-soluble oxidized $\mathrm{Hg}$. For this reason, it is important to understand the chemistry of the Hg-FGD gypsum interaction. The speciation of $\mathrm{Hg}$ in gypsum might have an important role in the understanding of $\mathrm{Hg}$ behaviour during coal combustion and its mobilization in water and land [5-7]. Chemical speciation methods such as the Ontario Hydro method [8] can give us information on the oxidation state of Hg but not the chemical species. However, Hg species can be identified by temperature programmed decomposition [9-20]. As a continuation of previous studies carried out by the authors $[9,17]$, the objective of this study is to prove that the thermal decomposition test is an efficient method for identifying mercury species from coal combustion products.

This method has been applied to identify Hg compounds in different type of solid samples [10-14]. However, there is a lack of knowledge concerning the speciation of Hg in coal combustion by-products [15], especially in gypsum samples [16-17]. Milobowski et al. [18] conducted a study on samples from wet flue gas desulfurization processes. The 
samples showed two thermal decomposition curves. In the first curve it was difficult to distinguish between $\mathrm{HgS}$ and $\mathrm{HgO}$ whereas the second curve corresponded well with $\mathrm{HgSO}_{4}$. Although any of the thermal evolutionary curves obtained from the pure mercury standards did not exactly match with those of the FGD gypsum and wallboard samples, Lee et al.[16] identified that $\mathrm{Hg}_{2} \mathrm{Cl}_{2}$ and $\mathrm{HgCl}_{2}$ could be the present species. When the thermal desorption method was used to identified $\mathrm{Hg}$ species in gypsum from a cocombustion plant the main species identified was $\mathrm{HgCl}_{2}$ [17]. Nowadays the use of biomass and systems to reduce NOx emissions could modify the behaviour of Hg during coal combustion and particularly in the FGD units. Gypsum samples from two Spanish pulverized coal (co) combustion power plants were tested using temperature programmed decomposition to identify different mercury species, leading to better understanding of Hg behaviour and its retention in FGD systems.

\section{Experimental}

The study was carried out in two 1200 MW Spanish power stations (A and B) equipped with a wet limestone-based with forced oxidation FGD facility. The power plant A burns a coal blend ranging from local sub-bituminous coals (60\%) close to lignite to bituminous coals (40\%). The power station B burns a blend of anthracites (80\%) and petroleum-coke (20\%). Gypsum samples were taken from the conveyor belt where the

dry gypsum is transported from the FGD unit to collection point. Subsequently the samples were stored in closed containers of polyethylene. Gypsum samples were called FGD-A and FGD-B from power station A and B, respectively. 
The experimental device has been described by the authors in previous works $[9,17]$. It consists of a thermal dissociation rig (PS Analytical Thermogram model 50.042) coupled to a mercury analyser (PS Analytical Sir Galahad Mercury Analyser model 10.525). The commercial thermal dissociation unit was modified to improve the temperature distribution along the work-tube between the programmed dissociation zone $\left(40-650^{\circ} \mathrm{C}\right.$ max) and the "cracker" zone (operated at $800^{\circ} \mathrm{C}$ ), where the volatilized mercury compounds are fully dissociated prior to detection as elemental mercury by the atomic fluorescence detector. The mercury compounds present in the solid sample are subjected to a programmed rise in temperature of $10^{\circ} \mathrm{C} \min ^{-1}$. A water trap of silica gel was integrated in the system just before the Sir Galahad detector.

Cold Vapour Atomic Fluorescence spectroscopy (CV-AFS) was used to determine the $\mathrm{Hg}$ contents in the samples. BET surface area was determined by volumetric adsorption of nitrogen at 77K. "Malvern Mastersizer-S” particle size analyzer was used for the particle size characterization.

\section{Results and discussion}

The FGD gypsum samples have a moisture content of approximately $20 \%$. Surface area, porosity, particle size and $\mathrm{Hg}$ concentration for gypsum samples are presented in Table 1. The Hg concentration in FGD gypsum samples was 0.15 and 0.31 $\mathrm{mg} \mathrm{kg}^{-1}$ for power plants A and B, respectively. No significance differences were found in the surface area, porosity and particle size between power station A burning a blend of coals and power station B burning a blend of pet-coke and coal. 
According to a previous study carried out by the authors [9], the thermal decomposition method allows the identification of individual $\mathrm{Hg}$ compounds as a function of $\mathrm{Hg}$ release with temperature. In this previous work the temperature appearance range of the main $\mathrm{Hg}$ species was arranged in increasing order as $\mathrm{HgCl}_{2}<\mathrm{HgS}<\mathrm{HgO}<\mathrm{HgSO}_{4}$. They are the most likely species to form during coal combustion and in a wet scrubber environment [18]. Because other halogens, such as $\mathrm{HgI}_{2}$ can be found in the effluent during coal combustion [7], the thermal decomposition for $\mathrm{HgI}_{2}$ has been included in this study. Figure 1 shows the thermograms for the studied $\mathrm{Hg}$ halogenated compounds. The order of the $\mathrm{Hg}$ appearance temperatures can be arranged in increasing order as $\mathrm{HgI}_{2}<\mathrm{HgBr}_{2}<\mathrm{HgCl}_{2}$. This order suggests that the thermal release of these $\mathrm{Hg}$ species is related to the electronegativity of the halogen, in that the Hg release temperature increases with electronegativity.

The thermal decomposition profiles for the gypsum samples were found different for both power stations A and B (Figure 2). In general, the thermal decomposition of $\mathrm{Hg}$ compounds in gypsum samples occurs at low temperature ranging from approximately 100 to $250{ }^{\circ} \mathrm{C}$. The FGD-A (Figure 2a) shows multiple but convoluted peaks with a maximum at $220{ }^{\circ} \mathrm{C}$. According to the decomposition temperatures for different $\mathrm{Hg}$ compounds [9], the decomposition for $\mathrm{Hg}$ sulphide and sulphate compounds occurs between $200-400^{\circ} \mathrm{C}$, therefore Hg-S species could be the mercury compounds present in the gypsum from power station A (burning blended coals), most probably Hg sulphate compounds. However, the mean peak obtained in the gypsum samples from power station B (burning a blend of coal and pet-coke) shows a maximum at approximately $140{ }^{\circ} \mathrm{C}$ (Figure 2b). These lower temperatures correspond to decomposition for Hg halogenated 
compounds [9], most probably $\mathrm{HgCl}_{2}$. The presence of chlorine in FGD gypsum was verified by Font et al. [21] for the same sampling campaign carried out in these two pulverized coal combustion power plants finding in fact, a higher chloride content in FGD-B than in FGD-A. Therefore, it is important to know the speciation of mercury in FGD gypsum because due to the different solubilities of Hg-S species (FGD-A) and $\mathrm{HgCl}_{2}$ (FGD-B), a different retention could be expected in the FGD units.

The thermal decomposition profile of FGD-A presents multiple peaks (Figure 2a) suggesting that some peaks might be overlapped. With the aim to improve the resolution between successive peaks, a second and revised heating programme was utilised. The heating programme consists of three ramps during which the temperature was raised at $20^{\circ} \mathrm{C} \mathrm{min}^{-1}$ separated by isothermal intervals of 7-10 minutes. The intervals were selected in order to allow each mercury compound to be completely resolved within its characteristic desorption temperature. Figure 3 shows the thermal decomposition profile for FGD-A using the multi-ramp temperature programme. The range of decomposition temperature is the same as that in Figure 2a. However, a sharp peak is now observed at approximately $220^{\circ} \mathrm{C}$ confirming that Hg-S species are the main mercury compounds in this gypsum. The second peak close to $120^{\circ} \mathrm{C}$ suggests that $\mathrm{HgCl}_{2}$ could be also present in FGD-A in very low concentration. X-ray Absorption Fine Structure (XAFS) studies have suggested that $\mathrm{Hg}$ in gypsum may be bound to Fe-containing particles in the presence of chloride [6, 22].

These results confirm the study carried out by Font et al. [21] over the partitioning of trace elements in the same two power plants. Font et al. found a higher Hg retention in FGD gypsum from power station A suggesting a major occurrence of insoluble $\mathrm{Hg}$ 
species in the FGD facilities (Figure 2a). In the power station B it was found a higher fraction of $\mathrm{Hg}$ in the water streams, indicating that $\mathrm{Hg}$ occurs as high water soluble $\mathrm{Hg}$ species (Figure 2b).

According to the physical and chemical characterization of the gypsum samples carried out in this study (Table 1), no significant differences were found between a power plant burning only coal and a power plant burning a blend of coal and pet-coke. However, differences were found when the samples were analyzed by the thermal decomposition method. Therefore, this method is a useful technique to gain a better understanding of Hg behaviour in FGD facilities.

\section{ACKNOWLEDGMENTS}

This work was supported by the project ABETRAP (RFCR-CT-2006-00006). The authors would like to thank INCAR (CSIC), IJA/IDEA (CSIC) and ENDESA. S.A. for providing the samples employed in this study and the programme of postdoctoral contracts abroad by Ministerio de Ciencia e Innovacion.

\section{REFERENCES}

[1]U.S. Environmental Protection Agency, Mercury http://www.epa.gov/mercury [2]Commission of the European Communities. Commission staff working paper. Annex to the Communication from the Commission to the council and the European Parliament 
on Community Strategy Concerning Mercury Extended Impact Assessment $\operatorname{COM}(2005) 20$ final

[3] $\underline{\text { http://ec.europa.eu/environment/chemicals/mercury/index.htm }}$

[4]Gale TK, Lani BW, Offen GR. Mechanisms governing the fate of mercury in coalfired power systems. Fuel Process Technol 2008;89:139-51.

[5]Kairies CL, Schroeder KT, Cardone CR. Mercury in gypsum produced from flue gas desulfurization. Fuel 2006;85:2530-6.

[6]Al-Abed SR, Jegadeesan G, Scheckel KG, Tolaymat T. Speciation, characterization, and mobility of As, Se, and $\mathrm{Hg}$ in flue gas desulphurization residues. Environ Sci Technol 2008;42:1693-8.

[7]Stergarsek A, Horvat M, Kotnik J, Tratnik J, Frkal P, Kocman D, et al. The role of flue gas desulphurisation in mercury speciation and distribution in a lignite burning power plant. Fuel 2008;87:3504-12.

[8]ASTM D6784-02. Ontario Hydro Method for Mercury in Flue Gas Generated from Coal-Fired Stationary Sources

[9]Lopez-Anton MA, Yuan Y, Perry R, Maroto-Valer MM. Analysis of mercury species present during coal combustion by thermal desorption. Fuel 2010;89:629-34.

[10]Windmoller CC, Wilken RD, Jardim WDF. Mercury speciation in contaminated soils by thermal release analysis. Water Air Soil Pollut 1996;89:399-416.

[11]Biester H, Gosar M, Covelli S. Mercury speciation in sediments affected by dumped mining residues in the drainage area of the Idrija Mercury Mine, Slovenia. Environ Sci Technol 2000;34:3330-6. 
[12]Ozaki M, Uddin MdA, Sasaoka E, Wu S. Temperature programmed decomposition desorption of the mercury species over spent iron-based sorbents for mercury removal from coal derived fuel gas. Fuel 2008;87:3610-5.

[13]Raposo C, Windmoller CC, Junior WAD. Mercury speciation in fluorescent lamps by thermal release analysis. Waste Manage 2003;23:879-86.

[14]Feng X, Lu JY, Gregoire DC, Hao Y, Banic CM, Schroeder WH. Analysis of inorganic mercury species associated with airborne particulate matter/aerosols: method development. Anal Bioanal Chem 2004;380:683-9.

[15]Li J, Yuan Y, Perry R, Maroto-Valer MM. Thermal desorption and speciation of mercury in fly ash. Prepr Pap-Am Chem Soc, Div Fuel Chem 2007;52(2):511-2.

[16]Lee J-Y, Cho K, Cheng L, Keener TC, Jagadeesan G, Al-Abed SR. Investigation of a mercury speciation technique for flue gas desulfurization materials. J Air Waste Manage Assoc 2009;59:972-9.

[17]Rallo M, Lopez-Anton MA, Meij R, Perry R, Maroto-Valer MM. Study of mercury in by-products from a Dutch co-combustion power station. J Hazard Mater 2010;174:2833.

[18]Milobowski MG, Amrhein GT, Kudlac GA, Yurchison DM. Wet FGD Enhanced Mercury Control for Coal-fired Utility Boilers, The U.S. EPA/DOE/EPRI Combined Power Plant Air. Pollutant Control Symposium: “The Mega Symposium” Chicago, Illinois, USA, 2001.

[19]Granite EJ, Pennline HW, Hargis RA. Novel sorbents for mercury removal from flue gas. Ind Eng Chem Res 2000;39:1020-9. 
[20]Granite EJ, Pennline HW, Hargis RA. Sorbents for mercury removal from flue gas. Report DOE/FETC/TR-98-01; National Energy Technology Laboratory: Pittsburgh, PA, Jan. 1998, pp 47.

[21]Font O, Izquierdo M, Ochoa-Gonzalez R, Leiva C, Lopez-Anton MA, Querol X, et al. Fate of trace pollutants in PCC-FGD power plants. Proceedings of 2009 World of Coal Ash (WOCA), May 4-7, Lexington, KY, USA, 2009, pp12.

[22]Kim CS, Rytuba JJ, Brown GEJr. EXAFS study of mercury (II) sorption to Fe- and Al-(hydr)oxides II. Effects of chloride and sulphate. J Col Int Sci 2004;270:9-20. 


\section{FIGURES CAPTIONS}

Figure 1. Thermal decomposition profiles of mercury halogenated compounds

Figure 2. Thermal decomposition profiles of (a) FGD-A and (b) FGD-B gypsums from A and B power station

Figure 3. Thermal decomposition profile of FGD-A gypsum using the multi-ramp temperature programme 